\title{
Polarity sensitivity of question embedding: experimental evidence*
}

\author{
Thom van Gessel \\ University of Amsterdam \\ Floris Roelofsen \\ University of Amsterdam
}

Alexandre Cremers
University of Amsterdam

\begin{abstract}
Attitude predicates can be classified by the kinds of complements they can embed: declaratives, interrogatives or both. However, several authors have claimed that predicates like be certain can only embed interrogatives in specific environments. According to Mayr, these are exactly the environments that license negative polarity items (NPIs). In his analysis, both NPIs and embedded interrogatives are licensed by the same semantic strengthening procedure. If this is right, one would expect a correlation between acceptability of be certain whether and NPIs. The analysis also predicts a contrast between antecedents vs. consequents of conditionals and restrictors vs. scopes of universal quantifiers. This paper tests these predictions experimentally through an acceptability judgment task. We find that judgments for be certain whether do not correlate with judgments on NPIs, which suggests that be certain whether and NPIs are in fact licensed by different mechanisms.
\end{abstract}

Keywords: clause-embedding predicates, selectional restrictions, negative polarity items

\section{Introduction}

Most attitude predicates are easy to classify by the kinds of complements they can embed. They are either rogative (only embedding interrogatives, e.g., wonder), anti-rogative (only embedding declaratives, e.g., believe) or responsive (embedding both types of complements, e.g., know).

However, it appears that there are also borderline cases such as be certain. Although this predicate is often classified as a responsive predicate (Karttunen 1977; Preuss 2001; Lahiri 2002; Uegaki 2015; Theiler, Roelofsen \& Aloni 2018),

* We are grateful to the audiences at the MiQ Workshop (Konstanz) and SALT 28 (MIT) for feedback. We also gratefully acknowledge funding from the European Research Council (ERC, grant number 680220) and the Netherlands Organisation for Scientific Research (NWO). 
some authors claim that it can only embed interrogative complements under specific circumstances (Egré 2008; Hölker 2014; Mayr 2017).

Specifically, Mayr (2017) argues that be certain whether can appear whenever negative polarity items (NPIs) can. For instance, on his view, be certain whether is degraded in positive sentences, but fine under negation, just like NPI any:

a. \#John is certain whether Mary smokes.

b. John is not certain whether Mary smokes.

a. \# John saw any girl.

b. John didn't see any girl.

This contrasts with predicates like know and believe: the former can always embed interrogatives, while the latter never can.

According to Mayr, it is not a coincidence that be certain whether and NPIs are licensed in the same environments: he hypothesizes that both NPIs and embedded interrogatives involve a semantic strengthening procedure which restricts their distribution, and he provides a formal analysis that implements this idea. The present paper is concerned with testing this analysis empirically.

We will start by reviewing some previous theoretical work, including Mayr's analysis, in section 2. At the end of this section, we point out three empirical issues that we want to address in this paper. In order to do this, we performed three experiments, which are described and discussed in section 3 . We will end with a conclusion and a discussion of further directions for research in section 4 .

\section{Previous theories}

\subsection{Adger \& Quer, Eckardt}

Before we turn to Mayr's theory, let us first briefly review some of the earlier related work on this topic.

Adger \& Quer $(1997,2001)$ observe that there exist predicates that normally only embed declarative complements, but can embed questions in negative environments. They call this phenomenon unselected embedded questions (UEQs) and offer a syntactic explanation. Their analysis is based on the stipulation that these embedded questions are headed by a silent operator, which is licensed by NPI licensers. Setting aside the issue that this stipulation may lack explanatory value, their account is also not fully satisfactory for the data that Mayr discusses, for two reasons.

First, their analysis mainly concerns if-clauses, and not whether-clauses. That is, the polarity sensitivity that Adger \& Quer are interested in is claimed to only occur with if, and not with whether. Further, the predicates know, admit, hear and say are discussed as examples of predicates that may take unselected embedded questions, 
Polarity sensitivity of question embedding

but they do not discuss be certain. Therefore, it is not clear how their analysis could be extended to capture the polarity sensitivity of be certain whether.

Second, although there indeed seem to be some proposition embedding predicates that allow for UEQs in certain contexts, there are also predicates that never allow interrogatives to be embedded, such as think or believe. This is not accounted for by Adger \& Quer.

Eckardt (2007) criticizes this syntactic approach and instead claims that the explanation should be sought in pragmatics. One of her criticisms of Adger \& Quer's analysis is that it cannot account for the polarity sensitivity of German sich sicher sein ob (which translates to be certain if/whether).

On Eckardt's view, the unacceptability of polar interrogative complements under some predicates in positive sentences is explained by competition with declarative complements:

a. \# John admits if Mary smokes.

b. John admits that Mary smokes.

Her assumption, following Bolinger (1978), is that the complement if $p$, in contrast to whether $p$, presupposes that $p$ is more relevant than $\neg p$. This would mean that (3a) presupposes that the fact that Mary smokes is worth admitting, while this is not the case for the fact that she does not smoke. It follows then, that (3a) can only be true if ( $3 b)$ is. The fact that the latter sentence is less complex should explain why the former is suppressed. This competition disappears under negation, which in turn explains the observed polarity sensitivity.

A problem with Eckardt's approach, however, is that it does not account for the case of be certain whether, for two reasons: first, whether is assumed not to have the asymmetric presupposition that if has. That means the theory could at most account for the polarity sensitivity of be certain if. The German example could only be accounted for as far as $o b$ has the asymmetric presupposition that if is said to have - but it is suggested that $o b$ is more like whether in this respect.

Second, even if we assume that John is certain if/whether Mary smokes presupposes that it is more relevant if Mary does smoke than if she does not, then from the statement that John is certain about either of the two propositions, it still does not logically follow that it has to be the first one. In the case where it is more relevant or surprising if Mary does smoke, it might still be worth mentioning that John is certain she does not. So it seems that in contrast to the predicate admit, the competition story does not go through with be certain. 


\subsection{Mayr's theory}

Mayr's account of the licensing of be certain whether is inspired by existing theories of NPI licensing (e.g., Krifka 1995; Chierchia 2013) that go roughly as follows.

Sentence (2a) has a literal meaning in which any is simply an existential quantifier. But it also has a strengthened meaning (obtained by an operator $E X H$ ) which is a combination of the literal meaning and the negations of all its non-weaker alternatives. Mayr assumes that the alternatives of (2a) are of the form John saw $x$, and that there is one such alternative for each girl $x .^{1}$

This strengthened meaning turns out to be systematically trivial (a contradiction), which should explain why the sentence is perceived as ungrammatical. Because the negation in (2b) reverses the direction of entailment, the alternatives of this sentence are in fact weaker than the literal meaning of the sentence itself, so the strengthened meaning will be the same as the literal meaning.

Mayr's analysis of be certain whether follows the same scheme. Again, the literal meaning of a sentence $\phi$ is strengthened by means of an exhaustivity operator $E X H$. This operator negates all formal alternatives of $\phi$ which are not Strawson-entailed by $\phi$ :

$$
\operatorname{EXH}(p)=\lambda w \cdot p(w) \wedge \forall q \in A L T(p)\left[p \not \Rightarrow_{S} q \rightarrow \neg q(w)\right]
$$

The formal alternatives of a sentence are constructed in a point-wise manner. Mayr assumes that the alternatives of a polar interrogative complement (whether $p$ ) are that $p$ and that not $p$.

The contrast between (1a) and (1b) can then be explained as follows: Since (1b) entails both of its alternatives, its strengthened meaning is the same as its literal meaning. In contrast, (1a) does not entail either of its alternatives. Their negations are therefore added to the strengthened meaning. But the literal meaning expresses that John is either certain that Mary smokes or that she does not. So combining this literal meaning with the negations of its alternatives will result in a contradiction. This explains the presumed degradedness of the sentence.

The fact that know whether and believe whether do not show this polarity sensitive behavior can also be explained by this theory.

(4) John knows whether Mary smokes.

$A L T$ : John knows that Mary smokes / John knows that Mary doesn't smoke

For know whether, the fact that Mayr uses the notion of Strawson entailment becomes relevant. To check whether (4) Strawson-entails an alternative, we have to check

1 This is different from the approach in Chierchia 2013: there, each alternative for (2a) replaces the contextually determined domain of girls that the existential quantifier ranges over with a subset of that domain. 
Polarity sensitivity of question embedding

whether it entails it under the assumption that the presupposition of the alternative is satisfied. Since know is factive, the alternatives both carry a presupposition that the embedded clause is true. So (4) indeed Strawson-entails both its alternatives, and applying $E X H$ will not have any effect. This correctly predicts that know whether is licensed both in positive and in negative environments.

Mayr further predicts that believe whether is never licensed. This prediction is based on the neg-raising property of believe: a sentence with believe presupposes that the subject either believes the complement or its negation. This makes (5a) a tautology: whenever its truth value is defined, it is true. By similar reasoning, it makes (5b) a contradiction.

a. John believes whether Mary smokes.

b. John does not believe whether Mary smokes

This explains why believe whether is not polarity sensitive: both with and without negation its meaning turns out to be trivial. ${ }^{2}$

\subsection{Empirical issues to address}

Mayr's analysis raises three issues that need to be addressed experimentally.

First, if the analysis is right, then we would expect that in a given environment, a speaker's acceptance of be certain whether should correlate with their acceptance of NPI any (see Chemla, Homer \& Rothschild 2011 for similar ideas and tests applied to Chierchia's predicted link between NPIs and scalar implicatures).

Second, apart from the contrast between (1a) and (1b), an analysis based on NPI licensing also predicts that be certain whether is fine in antecedents but not consequents of conditionals and in restrictors but not scopes of universal quantifiers, to the extent that NPIs are. ${ }^{3}$

Third, Mayr only discusses polar questions. If his analysis of be certain whether is right, the question arises how it should be extended to wh-complements. A first step in this direction is to test whether be certain wh exhibits the same polarity sensitivity as be certain whether.

2 See Theiler, Roelofsen \& Aloni 2017 for a similar account of the fact that believe does not take interrogative complements.

3 Mayr (2017) in fact expresses some doubt concerning the prediction that there be a contrast between restrictors and scopes of universal quantifiers when it comes to licensing be certain whether. 


\section{Experiments}

\subsection{Experiment 1}

\subsubsection{Goal}

The goal of our first experiment was to address the first two empirical issues mentioned above: First, we wanted to test Mayr's intuitions about the superficial pattern of acceptability of the construction be certain whether and to compare it with the NPI any. In addition, we decided to test whether the acceptability of the two constructions would correlate. Indeed, if their distribution is explained by the same mechanism, we expect participants who find any particularly degraded in a certain context to also find be certain whether equally degraded, and conversely for participants who would be more tolerant of a violation.

\subsubsection{Method}

We performed an acceptability judgment task through Mechanical Turk in which participants saw a collection of sentences, one at a time. Their task was to judge to what extent each sentence was acceptable, on a five point scale from odd to natural. The instructions included the following text:

A school class is having a geography quiz. The teacher asks questions like "Is Paris the capital of France?". When the children want to answer, they have to raise their hand.

Target sentences were of the form of (6a)-(6f), where COMP had the form of one of the complements in (7). ${ }^{4}$

a. Bob is certain COMP.

b. Madison is not certain COMP.

c. If Michael is certain COMP, then he will raise his hand.

d. If Chris raised his hand, then he is certain COMP.

e. Everyone who is certain COMP raised their hands.

f. Everyone who raised their hands is certain COMP. a. whether Milan is the capital of Italy or not

b. that Moscow is the capital of Russia (unembedded)

(negation)

(antecedent)

(consequent)

(restrictor)

(scope)

(interrogative)

(declarative)

4 With be certain, the city could either be the real capital city of the country or another major city to control for truth/falsity of the complement. However, declarative complements under know were constrained to always be true in order to satisfy the factive presupposition, while declarative complements under think were always false to satisfy the anti-presupposition of think (Percus 2006; Sauerland 2008). 
Polarity sensitivity of question embedding

\begin{tabular}{|c|c|c|c|c|}
\hline Predicate/determiner: & & Environment: & & Complement: \\
\hline $\begin{array}{l}\text { know } \\
\text { be certain } \\
\text { think }\end{array}$ & 1 & $\begin{array}{l}\text { unembedded } \\
\text { negation } \\
\text { antecedent }\end{array}$ & 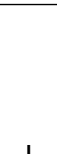 & $\begin{array}{c}\text { interrogative } \\
\text { declarative }\end{array}$ \\
\hline $\begin{array}{c}\text { any } \\
\text { a }\end{array}$ & $T$ & $\begin{array}{l}\text { consequent } \\
\text { restrictor } \\
\text { scope }\end{array}$ & $T$ & declarative \\
\hline
\end{tabular}

Table 1 Combinations of predicate/determiner, environment, and complement that were included in Experiment 1

We added control sentences with a different predicate (know, think) and sentences of the form (8a)-(8d), which contained NPI any in the same six environments, allowing us to test the correlation between the acceptability of any and be certain whether.

(8) a. The teacher asked any/a question about France.

b. The teacher did not ask any/a question about Germany.

c. If Sarah answers any/a question correctly, then she will receive any/a reward.

d. Everyone who answers any/a question correctly will receive any/a reward.

Associated control sentences had the indefinite $a$ in place of any.

See Table 1 for an overview of all combinations of predicates/determiners, environments and complement types. Each participant saw one of each possible combination (total: 48 items). The order of the items and the combinations of countries and capitals were randomized for each participant.

We recruited 100 participants (age range: 19-71), who were paid $\$ 0.70$ for their participation. The experiment took about $5 \mathrm{~min}$. One participant was removed from the analysis for reporting a native language other than English and 12 more because their error rate on controls exceeded the mean by more than one standard deviation. ${ }^{5}$

\subsubsection{Results}

The results are presented in Figure 1. The results for NPI any are as expected: high acceptability in downward-entailing environments (negation, restrictor, antecedent), much lower in upward-entailing environments. The picture is more complicated

5 The raw data and analysis scripts for all experiments are available online at https://semanticsarchive.net/Archive/DRhZTM3Y/vanGessel-Cremers-Roelofsen.html. 


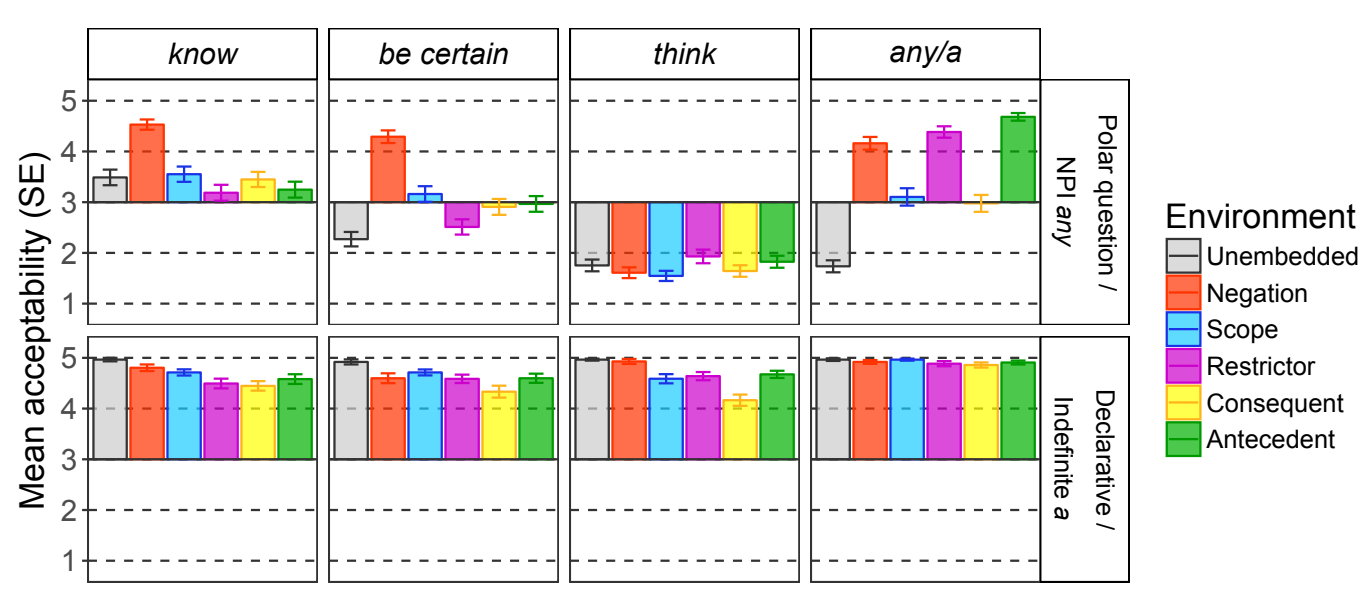

Figure 1 Results of Experiment 1: mean (SE) acceptability for each environment on a $1-5$ scale. The results for NPI any are presented in the same row as polar questions, while controls with $a$ are in the same row as declarative controls for know, be certain and think.

with be certain whether, which only seems clearly acceptable under negation, but the pattern for know is also rather different from what is usually assumed.

We compared the predicates be certain and know by running a linear mixed model on $z$-scored answers with PREDICATE, COMPLEMENT, ENVIRONMENT (baseline: negation) and all of their interactions as fixed effects. With declarative complements, the different environments varied in acceptability, but crucially this effect only marginally interacted with PREDICATE in the restrictor of universals $(t=$ $1.96, p=.0498$ ) but not in any other ENVIRONMENT (all $|t|<1.3, p>.20$ ). Under negation, questions were slightly degraded compared to declaratives $(t=-2.7, p=$ .006), but they were significantly more degraded in all other environments (all $t<-6.0, p<.001)$. We found no difference between the two predicates when they embed questions and are themselves embedded under negation $(t=.16, p=.88)$, but be certain was significantly degraded in comparison to know in plain affirmative sentences $(t=4.8, p<.001)$ and in the restrictor of universals $(t=3.2, p=.001)$. In short, we found a contrast between plain affirmative and negative sentences with both predicates, but it was stronger with be certain. In other environments, the picture is less clear.

We further tested the correlation between the acceptability of be certain whether and any. We found a small correlation across environments $\left(\chi^{2}(1)=4.9, p=.026\right)$ and no interaction with environment $\left(\chi^{2}(5)=6.9, p=.23\right)$. However, the individual 

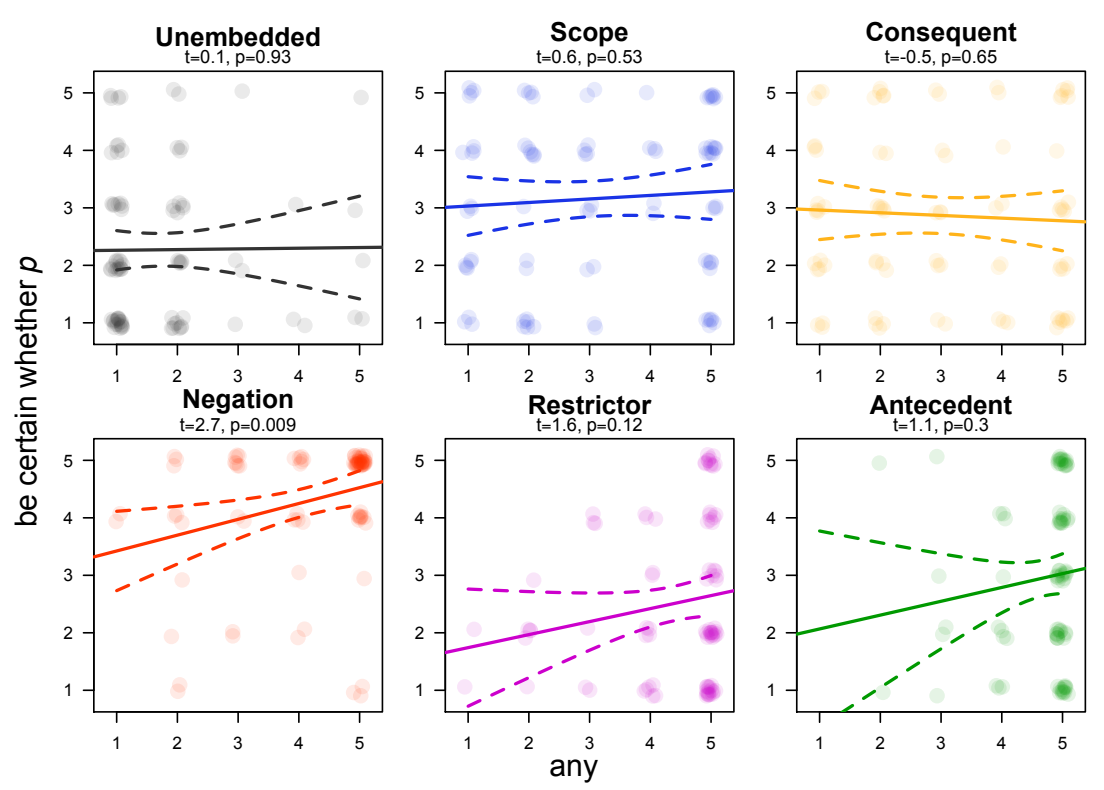

Figure 2 Experiment 1: Participants' response to be certain whether as a function of their response to any in each environment. Each patch of color corresponds to one participant. The correlation lines and corresponding $t$-values are fitted for each environment separately.

data broken down by environment in Figure 2 shows that this correlation is mainly driven by the three downward entailing environments, where both constructions are acceptable.

\subsubsection{Discussion}

In this experiment, we observed the usual pattern for NPI any, but the pattern for be certain whether differed on the more complex environments and the correlation between the two was rather limited. This may be related to the rather surprising and puzzling results for know. As a post-hoc analysis, we tested the effect of the truth/falsity of $p$ on the acceptability of whether $p$, but it did not interact with any other effect $\left(\chi^{2}(11)=12.4, p=.34\right)$.

\subsection{Experiment 2}

We hypothesized that the addition of or not to the polar interrogative complements may have caused the unexpected degradedness of variants with know whether. We ran a new experiment in which this was removed, and which contained animal 
classifications (e.g., tigers are mammals) instead of capital-country pairs which made complex sentences very long and possibly hard to process. It was otherwise the same.

We recruited 103 participants (age range: 22-70), who were paid $\$ 0.70$ for their participation. Two participants were removed from the analysis for reporting a native language other than English and 15 more because their error rate on controls exceeded the mean by more than one standard deviation.

The results were very similar. In the comparison between know and be certain, only the difference between the interactions with the Restrictor ENVIRONMENT weren't replicated $(t=0.8, p=.42$ for PREDICATE $\times$ ENVIRONMENT, $t=-1.2, p=$ .23 for PREDICATE $\times$ ENVIRONMENT $\times$ COMPLEMENT). The correlation between participants' answers to be certain whether and any wasn't replicated either $\left(\chi^{2}(1)=\right.$ $1.4, p=.23)$.

Crucially, know whether again showed polarity-sensitivity, suggesting that the or not in the polar questions of Experiment 1 did not play any particular role.

\subsection{Experiment 3}

\subsubsection{Goal}

We considered the possibility that the degradedness of know whether was due to competition with know that. Crucially, while know that may be preferred over know whether in case their complement is known to be true, if the truth value of the complement is not known, this competition should be blocked. Therefore, in our final experiment the animal classification context was replaced by one with fictional properties of aliens. Since participants cannot have any prior knowledge about these properties, this should rule out any expectations about their truth or falsity.

Finally, we set out to address our last empirical issue, regarding the generalizability of the pattern to $w h$-questions. We therefore tested which-questions in all environments, to see to what extent they behave like polar whether-questions.

\subsubsection{Method}

Like in the previous experiments, target sentences were of the form of (6a)-(6f). This time, COMP had the form of one of the complements in (9).

$$
\begin{aligned}
& \text { a. whether the Ikreht aliens are fluffy } \\
& \text { b. which aliens are speckled } \\
& \text { c. that the Gryjihq aliens are red }
\end{aligned}
$$

(polar interrogative complement) (wh-complement) (declarative complement)

Control sentences with know followed the same scheme, and fillers with think and 
Polarity sensitivity of question embedding

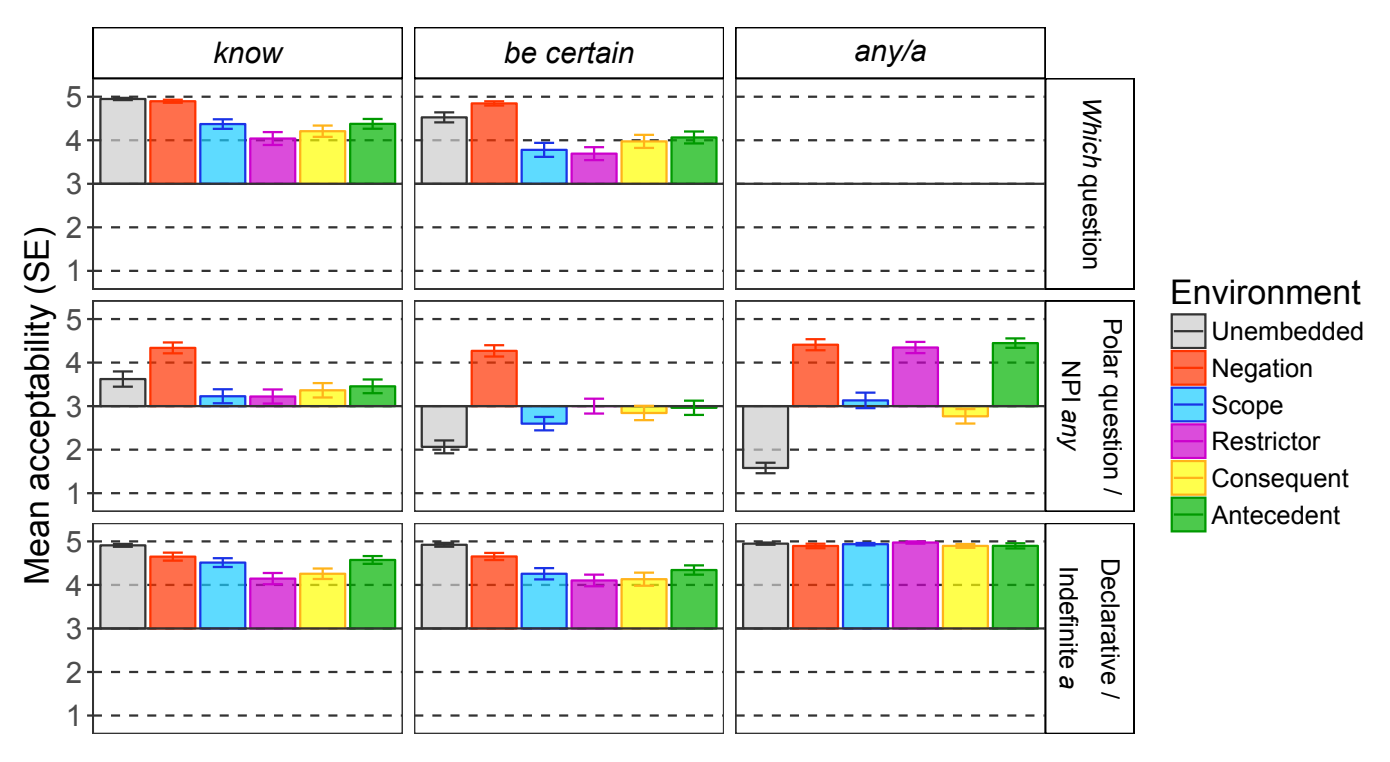

Figure 3 Results of Experiment 3: mean (SE) acceptability for each environment on a 1-5 scale. The results for NPI any are presented in the same row as polar questions, while controls with $a$ are in the same row as declarative controls for know and be certain.

wonder were included to balance the ratio of expected odd/natural responses. As before, sentences with NPI any in the same environments and associated control sentences with $a$ were added. The order of the items was randomized, as well as the combinations of aliens and properties.

89 participants were recruited on Mechanical Turk and paid \$1 for their participation (age range: 22-62). The experiment took about 7 minutes. All participants reported English as their native language, but 11 participants who exceeded the mean error rate by at least one standard deviation were removed from the analysis.

\subsubsection{Results}

The results are presented in Figure 3. As in the previous experiments, we ran a model to compare know and be certain, this time with three levels for COMPLEMENT (declarative, polar question, which-question). The results for declarative and polar question complements were very similar: no difference between the verb with declarative complements, no difference with question when embedded under negation, but in other environments both verbs were significantly degraded with 

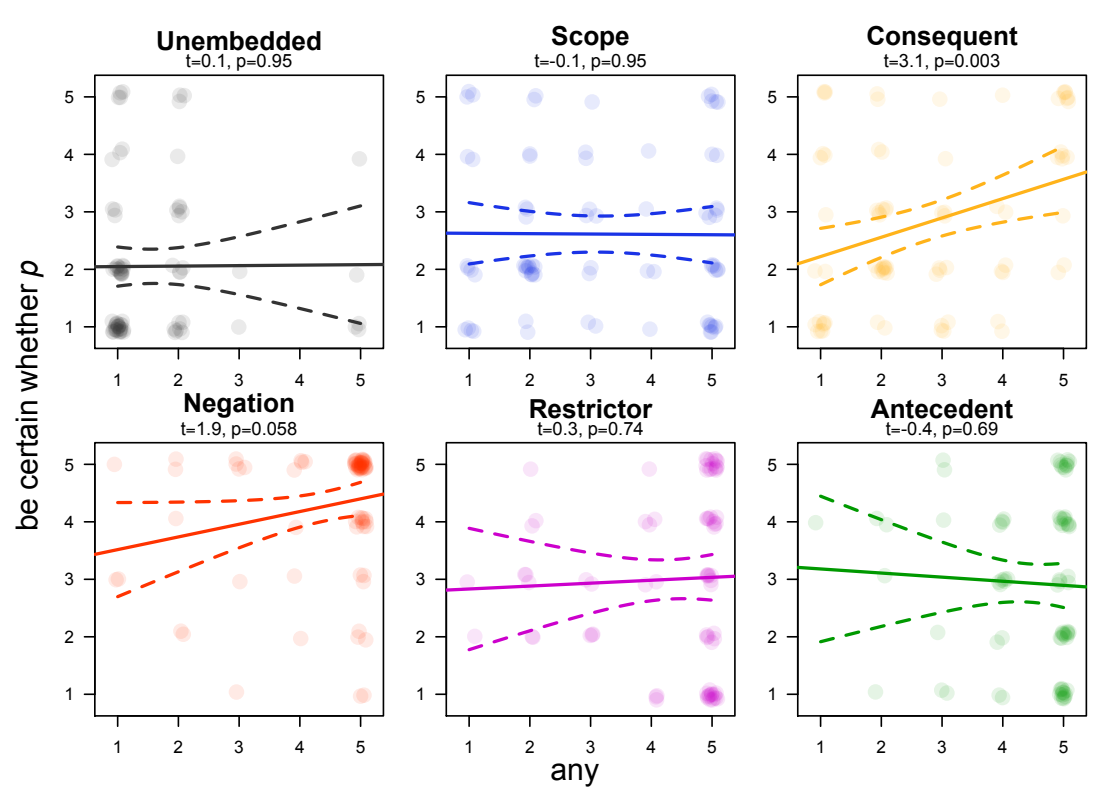

Figure 4 Experiment 3: Participants' response to be certain whether as a function of their response to any in each environment. Each patch of color corresponds to one participant. The correlation lines and corresponding $t$-values are fitted for each environment separately.

polar question (all $t<-3.8, p<.001$ ), and be certain was even more degraded in plain affirmative sentences $(t=-5.5, p<.001)$. Which-questions were rated higher than declarative complements in negative environment $(t=2.2, p=.025)$, but in other environments they were equally or less acceptable (all $t<-2.2, p<.028$ ). Here there was no difference between the two verbs (all $|t|<1.4, p\rangle .16$ ).

We found a significant correlation between the judgments for be certain whether and any $\left(\chi^{2}(1)=4.2, p=.041\right)$. Once again, looking at the details in Figure 4 shows that this effect is mainly driven by Negation and, this time, Consequent.

\section{Conclusions and further work}

Our results suggest that be certain whether is indeed degraded in positive episodic sentences. Moreover, they confirm that this effect disappears under negation. In these two sentence types, be certain whether shows a similar overall pattern as NPIs, confirming Mayr's judgment.

However, when looking at individual participants, judgments for be certain whether do not generally correlate with judgments on NPIs. Furthermore, the similarity found in plain positive and negative sentences does not seem to extend 
Polarity sensitivity of question embedding

to conditionals and quantified sentences. This suggests that be certain whether and NPIs are (anti-)licensed by different mechanisms.

Two more pieces of data are worth highlighting as well: first, Experiment 3 shows that be certain is much less polarity sensitive with which-questions than with whether-questions; and second, quite unexpectedly, know whether appears to be somewhat polarity sensitive, similar to be certain whether. Note that according to Mayr's analysis know is not polarity sensitive at all, because it is factive, in contrast to be certain. More work is needed, however, to determine what causes these effects.

The fact that our results do not support a unified analysis of be certain whether and NPI any does not necessarily mean that the analysis based on exhaustification is not on the right track for any of the two phenomena. If we give up the unified analysis, there are still two options.

The first option is to give up the exhaustification analysis of NPI any (this is somewhat suggested by Chemla et al. 2011). It can also be adapted in several ways: for instance, Chierchia (2013) offers a more refined version of the exhaustification story than Mayr does, which is required to deal with quantified cases.

A second option is to give up Mayr's analysis of be certain whether. Although there is no fully satisfactory explanation available yet, we do want to suggest two directions that seem worth further investigation.

First, since the acceptability of be certain whether is higher under negation than in the restrictor of a universal quantifier or the antecedent of a conditional, it seems that be certain whether is more similar to strong NPIs like in years than to weak NPIs like any. Roughly, weak NPIs are licensed in all downward entailing environments, while strong NPIs are only licensed in a subset of those environments, namely ones that are anti-additive (Zwarts 1998). For instance, in years is not licensed in the restrictor of a universal quantifier or in the antecedent of a conditional, which are not anti-additive environments.

(10) a. *Everyone who has gone hiking in years should be in good shape.

b. *If Sue goes hiking in years she will be in good shape.

On the other hand, in years is licensed under sentential negation, under negative quantifiers like none of my friends and under without, which do create anti-additive environments.

(11) a. Sue hasn't gone hiking in years.

b. None of my friends has gone hiking in years.

c. Sue attempted the Mont Blanc this summer without having hiked in years.

These anti-additive environments are ones in which be certain whether seems 
perfectly acceptable as well:

a. John isn't certain whether Sue likes to hike.

b. None of my friends is certain whether Sue likes to hike.

c. Sue went hiking without being certain whether it would rain or not.

These observations suggest that it would be worth investigating whether there is indeed a general correlation between the acceptability of be certain whether and that of strong NPIs like in years. If this is indeed the case, this should guide our further theoretical analysis of the polarity sensitive nature of predicates like be certain.

Second, in positive sentences be certain behaves similar to emotive factive predicates like surprise, in the sense that these are also incompatible with whethercomplements, but not with wh-complements:

a. \#It surprises Mary whether John showed up.

b. It surprises Mary who showed up.

According to Herbstritt (2014); Roelofsen, Herbstritt \& Aloni (2016); Roelofsen (2017), the fact that emotive factives like surprise do not license whethercomplements is related to the strong existential presupposition they trigger when taking a wh-complement, witnessed by the oddness of (14a) compared to (14b):

a. \#It surprises Mary who showed up, if anyone.

b. Bill will tell Mary who showed up, if anyone.

Interestingly, we observe that be certain, when taking a wh-complement, seems to trigger the same kind of existential presupposition in positive environments, but not in negative ones: 6

a. \# John is certain who smokes, if anyone.

b. John isn't certain who smokes, if anyone.

If this contrast indeed exists, the explanation of why emotive factives are incompatible with whether-complements may carry over to be certain in positive environments. Further work is needed, however, to experimentally confirm the contrast in (15), and to understand why this presupposition would be polarity sensitive.

For now we conclude that our results confirm the polarity sensitivity of be certain whether, but challenge Mayr's hypothesis that the same mechanism is responsible for both unlicensed NPIs and the degradedness of be certain whether in positive sentences.

6 Our results suggest that (15a) is slightly degraded even without if anyone, but the native speakers we consulted agreed that there is a clear contrast between the sentences with and without if anyone. 
Polarity sensitivity of question embedding

\section{References}

Adger, David \& Josep Quer. 1997. Subjunctives, unselective embedded questions, and clausal polarity items. North East Linguistic Society (NELS) 27 1-15.

Adger, David \& Josep Quer. 2001. The syntax and semantics of unselected embedded questions. Language 77(1). 107-133. doi:10.1353/lan.2001.0001.

Bolinger, Dwight. 1978. Yes-no questions are not alternative questions. In Henry Hiż (ed.), Questions, 87-105. Dordrecht: Springer Netherlands. doi:10.1007/978-94-009-9509-3_3.

Chemla, Emmanuel, Vincent Homer \& Daniel Rothschild. 2011. Modularity and intuitions in formal semantics: The case of polarity items. Linguistics and Philosophy 34(6). 537-570. doi:10.1007/s10988-012-9106-0.

Chierchia, Gennaro. 2013. Logic in Grammar. Oxford University Press.

Eckardt, Regine. 2007. The syntax and pragmatics of embedded yes/no questions. In Kerstin Schwabe \& Susanne Winkler (eds.), On Information Structure, Meaning, and Form, 447-466. Amsterdam: John Benjamins. doi:10.1075/la.100.24eck.

Egré, Paul. 2008. Question-embedding and factivity. Grazer Philosophische Studien 77(1). 85-125. doi:10.1163/18756735-90000845.

Herbstritt, Michele. 2014. Why can't we be surprised whether it rains in Amsterdam? A semantics for factive verbs and embedded questions.

Hölker, Klaus. 2014. On being certain whether. In Andrzej Zuczkowski, Ramona Bongelli, Ilaria Riccioni \& Carla Canestrari (eds.), Communicating Certainty and Uncertainty in Medical, Supportive and Scientific Contexts, 79-98. John Benjamins Publishing Company. doi:10.1075/ds.25.04hol.

Karttunen, Lauri. 1977. Syntax and semantics of questions. Linguistics and Philosophy 1(1). 3-44. doi:10.1007/978-94-009-9509-3_6.

Krifka, Manfred. 1995. The semantics and pragmatics of polarity items. Linguistic Analysis 25(3-4). 209-257.

Lahiri, Utpal. 2002. Questions and Answers in Embedded Contexts. Oxford University Press.

Mayr, Clemens. 2017. Predicting polar question embedding. Sinn und Bedeutung $211-18$.

Percus, Orin. 2006. Antipresuppositions. In Ayumi Uyema (ed.), Theoretical and Empirical Studies of Reference and Anaphora: Toward the Establishment of Generative Grammar as an Empirical Science, 52-73. Japan Society for the Promotion of Science.

Preuss, Susanne. 2001. Issues in the Semantics of Questions with Quantifiers. New Brunswick, New Jersey: Graduate School-New Brunswick dissertation.

Roelofsen, Floris. 2017. Surprise for Lauri Karttunen. In Cleo Condoravdi (ed.), Lauri Karttunen Festschrift, Stanford: Center for the Study of Language and 
Information.

Roelofsen, Floris, Michele Herbstritt \& Maria Aloni. 2016. The *whether puzzle. To appear in Questions in Discourse, edited by Klaus von Heusinger, Edgar Onea, and Malte Zimmermann.

Sauerland, Uli. 2008. Implicated presuppositions. In A. Steube (ed.), Sentence and Context: Language, Context, and Cognition, 581-600. Berlin: Mouton de Gruyter. doi:10.1515/9783110209303.4.581.

Theiler, Nadine, Floris Roelofsen \& Maria Aloni. 2017. What's wrong with believing whether? Semantics and Linguistic Theory (SALT) 27 248-265. doi:10.3765/salt.v27i0.4125.

Theiler, Nadine, Floris Roelofsen \& Maria Aloni. 2018. A uniform semantics for declarative and interrogative complements. Journal of Semantics 35(3). 409-466. doi:10.1093/jos/ffy003.

Uegaki, Wataru. 2015. Interpreting Questions under Attitudes. Cambridge, Massachusetts: Massachusetts Institute of Technology dissertation.

Zwarts, Frans. 1998. Three types of polarity. In Fritz Hamm \& Erhard Hinrichs (eds.), Plurality and Quantification, 177-238. Kluwer Academic Publishers. doi:10.1007/978-94-017-2706-8_5.

Thom van Gessel

Science Park 107

1098 XG Amsterdam

mail@thomvangessel.nl

Floris Roelofsen

Science Park 107

1098 XG Amsterdam

floris.roelofsen@gmail.com
Alexandre Cremers

Science Park 107

1098 XG Amsterdam

alexandre.cremers@gmail.com 